Resumode Tese

\title{
Modificações das Gonadotrofinas na Pausa da Anticoncepção Hormonal Oral Combinada, com 20ug de Etinilestradiol.
}

\section{Gonadotrofin changs in the pause of an oral contraceptive containing $20 \mu \mathrm{g}$ of ethynylstradiol}

Autor: Dalton Ferreira

Orientador: Prof. Dr.Sebastião Freitas de Medeiros

Dissertação apresentada ao Instituto de Saúde Coletiva da Universidade Federal de Mato Grosso para obtenção de título de Mestre em Saúde e Ambiente, em 12 de março de 2003.

A proposta deste estudo foi avaliar as variações do FSH e LH em usuárias de um anticoncepcional hormonal oral contendo $20 \mu \mathrm{g}$ de etinilestradiol (EE) $+75 \mu \mathrm{g}$ desogestrel (DSG). Incluiram-se no estudo 31 mulheres com idade entre 17 a 36 anos. Niveis séricos de hormônio folículo estimulante (FSH), hormônio luteinizante (LH), prolactina (PRL) e estradiol foram verificados no dia de ingestão do último comprimido de uma cartela e no $7^{\circ}$ dia de pausa entre duas cartelas. Durante o uso do contraceptivo observou-se acentuado grau de atenuação nos niveis séricos de FSH, LH e estradiol. Na pausa entre as cartelas houve recuperação dos niveis das gonadotrofinas e estradiol na or- dem de 300\% e 39\% respectivamente. Os niveis de prolactina apresentaram um decréscimo de 23,5\% durante a pausa da pilula. Como a medida das gonadotrofinas no último dia da pausa do anticoncepcional mostrou ser menor que o nível observado na fase folicular precoce das pacientes não usuárias , poder-se-ia utilizá-la como marcador para suspensão do anticoncepcional hormonal oral nas pacientes climatéricas, sem elevar o risco de gravidez indesejada nesta fase da vida.

Palavras-chave: Hormônio folículo estimulante. Hormônio luteinizante. Contracepção.

\section{Prevalência de Hipotireoidismo e Caracteristicas Clínicas Associadas à Hipofusão Tireoideana entre Mulheres Climatéricas. Um Estudo de Base Hospitalar.}

\author{
Prevalence of Hypothyroidism and its clinical characteristics in climacteric \\ women: A hospital-based study
}

Autor: Valmir Aparecido Franco

Orientador: Prof. Dr.Sebastião Freitas de Medeiros

Dissertação apresentada ao Instituto de Saúde Coletiva da Universidade Federal de Mato Grosso para obtenção de título de Mestre em Saúde e Ambiente, em 30 de outubro de 2003.

Os métodos atuais para quantificar o hormônio estimulador da tireóide (TSH), a tiroxina (T4) e a tiroxina livre (T4L) permitiram o reconhecimento das formas subclinica e clínica de hipotireoidismo. O objetivo deste estudo, de corte transversal, foi avaliar a prevalência de hipotireoidismo em 168 mulheres de 40 a 65 anos atendidas nos ambulatórios do Departamento de Ginecologia e Obstetrícia do Hospital Universitário Júlio Muller, em Cuiabá-MT. A idade média das mulheres foi de 48,9 anos, a maioria era de casadas $(70,8 \%)$, não-brancas $(53,6 \%)$, não-tabagistas, abstinência de álcool $(64,5)$, baixa escolaridade $(94,0 \%)$ e migrantes de outros estados $(51,8 \%)$. Em relação à classe social, encontrou-se que $78,6 \%$ delas pertenciam às classes "D e E". O peso corporal médio foi de $68,0 \mathrm{~kg}$ e a estatura média 1,55 metros. A análise do índice de massa corpórea mostrou que $31,5 \%$ eram obesas e $36,3 \%$ sobrepeso. A idade média da menarca foi de 13,3 anos e a paridade média foi de 4,8 gestações por mulher. A ligadura de trompas $(72,1 \%)$ e a histerectomia $(23,0 \%)$ foram as cirurgias ginecológicas mais freqüentes. Das doenças pré-existentes, as mais prevalentes foram hipertensão arterial $(46,4 \%)$ e diabetes mellitus $(20,2 \%)$. Dos sintomas referidos, diminuição de memória $(65,5 \%)$, nervosismo $(64,9 \%)$, fogachos $(57,1 \%)$ e redução da libido $(62,3 \%)$ foram os mais freqüentes. A prevalência de hipotireoidismo foi de 17,9\% (30/168). O hipotireoidismo foi associado à maior prevalência de depressão $(p=0,005)$, diminuição da memória $(p<0,001)$, sonolência $(p=0,016)$ e sensação de frio $(p, 0,001)$ e a menor prevalência de fogachos $(p=0,012)$ e nervosismo $(p=0,002)$. Não mostrou correlação com sudorese $(p=0,622)$, insônia $(p=0,655)$, tontura $(p=0,670)$, taquicardia $(p=0,435)$ e artralgia $(p=0,817)$. Pela elevada prevalência, e intima relação com a idade e sexo feminino, conclui-se ser importante o rastreamento do hipotireoidismo no climatério.

Palavras-chave: Hipotireoidismo. Climatério. Hormônio estimulador da tireóide. TSH. Tiroxina. 